\section{食品添加物に関する研究（第 $\mathbf{1}$ 報） 食品よりデヒドロ酢酸の分離定量法の検討}

佐谷戸安好* 仲田 典子* 岡琦 政智* 西条 達也*

食衛誌. 7(3)，119～203（1966）

食品に含まれるデヒドロ酢酸 (DHA) の分離測定につ いて抽出法, 加水蒸留法および水蒸気蒸留法の 3 者によ る比較分離を行なった，その結果, 水蒸気蒸留法が他の 2 法に比べ，回収時比較的妨害が少なくデンプン食品で $96.5 \%$ の好回収結果を示した。水蒸気蒸留に際しては, あらかじめ試料に食塩を飽和したのち 酒石酸 $0.7 \mathrm{~g}$ を入 れて蒸留し, 留液を $0.5 \mathrm{~N} \mathrm{NaOH}$ 溶液 $4 \mathrm{ml}$ 中にうけ留 液量を $100 \mathrm{ml}$ うけ, これを紫外部吸光度測定法により 波長 $290 \mathrm{~m} \mu$ で定量することによってジュース，しょう 油, デンプン食品，バター，チーズ等より DHA を分離 定量できる結果を得た。

* 茨城県立衛生研究所

\section{食用色素 Ponceau 3R の慢性毒性ならびに 発癌性に関する研究}

相磯 和嘉* 蟹沢 成好*

岡本 達也* 中條 朋子*

食衛誌. 7(3)，211～221（1966）

食用赤色タール色素 Ponceau 3R の慢性経口程性な らびに発癌性を，ラットで最長 2 年にわたり $2.0 \%, 1.0$ $\%$ および $0.5 \%$ 添加食投与により病理組織学的に検索し た。変化は肝臓に限られ，脂肪変性を中心に各種退行変 性が実験早期より出現したが，肝硬変の発生はなかっ た. 増殖性変化は実験 1 年以上の動物に多発し， 1 年 7 か月で腺腫の発生があり，実騟 2 年で 1 例の肝癌と 5 例 の多発性腺腫を含む高率の腫瘍性病変の発生を認めた。

* 千葉大学腐敗研究所

\section{魚肉ソーセージおよびちくわの貯蔵中 における腐敗生成物の消長}

坂部 美雄* 不原 利克* 食衛誌. 7(3)，226～229（1966）

魚肉ソーセージおよびちくわを冷蔵庫と $20^{\circ}$ 恒温庫に 貯蔵して腐敗生成物の変化について調べた。

腐敗の発見因子としては揮発性塩基窒素が最 適であ る.ちくわでは揮発性還元物質も発見因子になりうる. 魚肉ソ一セージは遊離ヒスチジンがかなり存在し腐敗と ともに減少するが，七スタミンは検出されない。冷蔵庫 中では両者ともに腐敗生成物の生成は少ない。

* 名古屋市衛生研究所

\section{溶媒抽出法およびイオン交換樹脂応用 による数種の保存料の分離定㽚 \\ 井上哲男 $* 1$ 河村太郎*1 上篠昌弥*1 佐藤洋子*1 菅野三郎*2 落合昭吾*2 中岡正吉*2 \\ 食衛誌. 7(3)，204～210（1966）}

食品中の保存料の分別定量を目的として溶媒抽出およ びイオン交換樹脂と紫外部吸収スペクトル測定との組合 せによる方法について検討した。

保存料としてデヒドロ酢酸，ソルビン酸，安息香酸， サリチル酸，およびパラオキシ安息香酸のエステル類の 5 種を用いた。

本法の特徵はつぎの諸点である。

(1)四塩化炭素によりサッカリンは不溶であり，保存料 は可溶なので同者の分離が可能である.(2)イオン交換樹 脂 (Amberlite CG 400-I 型) を使用することによりサ リチル酸は他の保存料と分離される.(3)イオン交換樹脂

(Amberlite CG 400-I 型) を使用することは食品に起 因する妨害を除去するのに有効である。本法を市販食品 のジュース，漬物類に応用しその結果を報告した。

*1 横浜市衛生研究所

*2 神奈川県衛生研究所

\section{キレート試薬を用いた分光光度滴定法 による食品中の銅の分析}

鹿島 哲*1 天野立爾*2 武見和子*2 川公平*2 川城 嚴 ${ }^{2 *}$

食衛誌. 7(3)，222～225（1966）

10〜100 $\mu \mathrm{g}$ の銅を含む試料に緩衝液を加えて $\mathrm{pH} 4.5$ 〜 6にした試料液を $0.01 \mathrm{M}$ または $0.001 \mathrm{M}$ エチレンジア ミン 2 プロピオン酸標準液で $261 \mathrm{~m} \mu$ の単色光を用いて 光度滴定したところ, $\mathrm{Ca}(\mathrm{II}), \mathrm{Mg}(\mathrm{II}), \mathrm{Ni}(\mathrm{II}), \mathrm{Pb}(\mathrm{II})$ および $\mathrm{Hg}(\mathrm{II})$ が共存していても $1 \%$ 以内の測定精度 で定量できることを見いだしたので，グリンピース，ピ 一ナッツ,ココアまめなどの試料 $10 \mathrm{~g}$ を灰化し，緩衝液 で $\mathrm{pH}$ 4.5〜 5. 6 として光度滴定したところ，その食品中 の微量の銅を定量することができた。

$* 1$ 共立薬科大学:

*2 国立衛牛試験所

\section{ペプシンのタンパク消化作用に対する}

\section{食用，医薬品用色素の影響について}

\author{
古武彌三* 水田泰子* 樫本 隆*
} 食衛誌。7(3)，230～233（1966）

食用, 医薬品用色素はペプシンのタンパク消化作用に 対して阻害を示すが，とくに xanthene 系の Phloxine (赤色104号), Rose Bengale(赤色105号)は強く阻害す る. 阻害作用は Phloxine, Rose Bengale などの色素が ペプシン酵素に直接結合するためであると考えられる. Phloxine のペプシン阻害性は色素酸として遊離される 酸性 medium においてのみ現われる。

* 大阪府立公衆衛生研究所 


\title{
溶媒抽出法新よびイオン交換樹脂応用による 数種の保存料の分離定量*1
}

（昭和 41 年 1 月 28 日受理)

\begin{tabular}{|c|c|c|}
\hline 井上 哲 男*2 & 河 村 太 郎*2 & 上條昌弥 ${ }^{* 2}$ \\
\hline 佐 藤 洋 子*2 & 菅 野 三 郎*3 & 落 合 昭 吾*3 \\
\hline
\end{tabular}

Differential Determination of Several Kinds of Preservatives in Foods by Extraction and Ion Exchange Resin Methods
Tetsuo INOUE*2, Taro KAWAMURA*2, Masaya KAMIJO*2, Yōko SATŌ*2, Saburo KANNO*3, Shogo OCHIAI*3, and Tadayoshi NAKAOKA*3
(*2Yokohama Municipal Public Health Laboratory: 2-102, Nakamura-cho, Minami-ku, Yokohama; *3Kanagawa Prefectural Public Health
Laboratory: 52-2, Nakao-cho, Hodogaya-ku, Yokohama)

\begin{abstract}
For the purpose of the differential determination of the preservatives in foods, the combination method of the procedures of solvent extraction, ion exchange resin and ultraviolet absorption spectra was studied.

As the preservatives five kinds of substances were taken up, namely, benzoic acid (BA), p-hydroxybenzoic acid esters (PHBA-E), sorbic acid (SOA), dehydroacetic acid (DHA) and salicylic acid (SA).

Characteristic points of this method were as follows:
\end{abstract}

(1) Saccharin was removed from the mixture of preservatives by $\mathrm{CCl}_{4}$ extraction.

(2) SA was separated from the other preservatives by ion exchange resin.(Amberlite CG $400-\mathrm{I})$

(3) Ion exchange resin (Amberlite CG 400-I) was useful to remove the interference accompanied with foods.

This method was applied to the market foods, for example, juices or pickles, and the results obtained were reported.

(Received January 28, 1966)

\section{I まえがき}

われわれは前報1)において，水蒸気蒸留法による食品 中の数種の保存料の分離定性定量法について報告した.

溶媒による抽出法は，タンパク質や糖質を多く含む食

*1 井上哲男, 河村太郎, 上條昌弥, 佐藤洋子：食品中 の防腐剂に関する研究（第 7 報）

菅野三郎, 落合昭吾, 中岡正吉 : 食品添加物の分析 に関する研究（第11報）

*2 横浜市衛生研究所 : 横浜市南区中村町 2-102

*3 神奈川県衛生研究所 : 横浜市保土ケ谷区中尾町52-2
品および乳化剤を使用している食品では，はなはだしい 乳化現象を起こし，操作がきわめて困難となる場合が少 なくない.また溶媒抽出法では使用する有機溶媒に可溶 の物質はすべて抽出され，二次的に抽出された物質が目 的物の定性定量を困難にする場合もしばしばある.

そこでわれわれは安息香酸 (BA)，パラォキシ安息香 酸エステル類 (PHBA-E), ソルビン酸 (SOA), サリチ ル酸 (SA)，デヒドロ酢酸 (DHA) 等数種の酸性保存料 およびサッカリンが共存する場合を想定し，従来の溶媒 抽出法にイオン交換樹脂を利用することにより分離定量 
がほぼ可能であることがわかったので，以下に報告す る.

本法の骨子はFig. 2 に示すように各保存料を含む試料 溶液をはじめアルカリ性でェーテルを用い中性, 塩基性 物質を除いたのち，つぎに酸性でエーテル抽出を行ない この抽出液から， $1 \%$ 炭酸水素ナトリウム溶液を用いて PHBA-E を他の保存料と分離したのち, エーテル留去残 留物に四塩化炭素を加えて不溶のサッカリンを除去し， サッカリンを除いた保存料を Amberlite CG 400-I 型 イオン交換樹脂を用いて SA と他の保存料とに分離し, それぞれのフラクションについて試験溶液を調製し，以 下前報のように紫外部吸光度測定法を行なう。

\section{II 実験方法}

\section{〔装置〕}

1. イオン交換樹脂クロマト管：内径 $1 \mathrm{~cm}$ ，長さ 30 $\mathrm{cm}$, 下端に活栓コック付のクロマト管に常法に従い精 製した Amberlite CG400-I 型(-Cl 形)約 $4.5 \mathrm{ml}$ を $5 \mathrm{~cm}$ の高さに充填したもの.

2. 自記分光光度計

\section{[試 薬]}

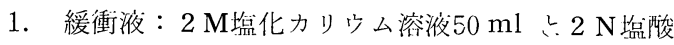
$10.6 \mathrm{ml}$ を混合し，水を加えて $200 \mathrm{ml}$ とする.

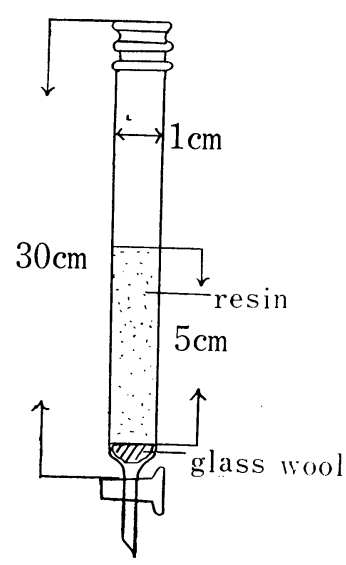

Fig. 1. Apparatus

Ion-exchange resin: Amberlite CG 400-I type (anion exchange resin, Cl-type) Elute: $0.1 \mathrm{~N} \mathrm{HCl}, 0.1 \mathrm{~N} \mathrm{HCl}$ with $60 \%$ Ethanol, Flow Rate: $1 \mathrm{ml} / \mathrm{min}$, Temperature : room temperature

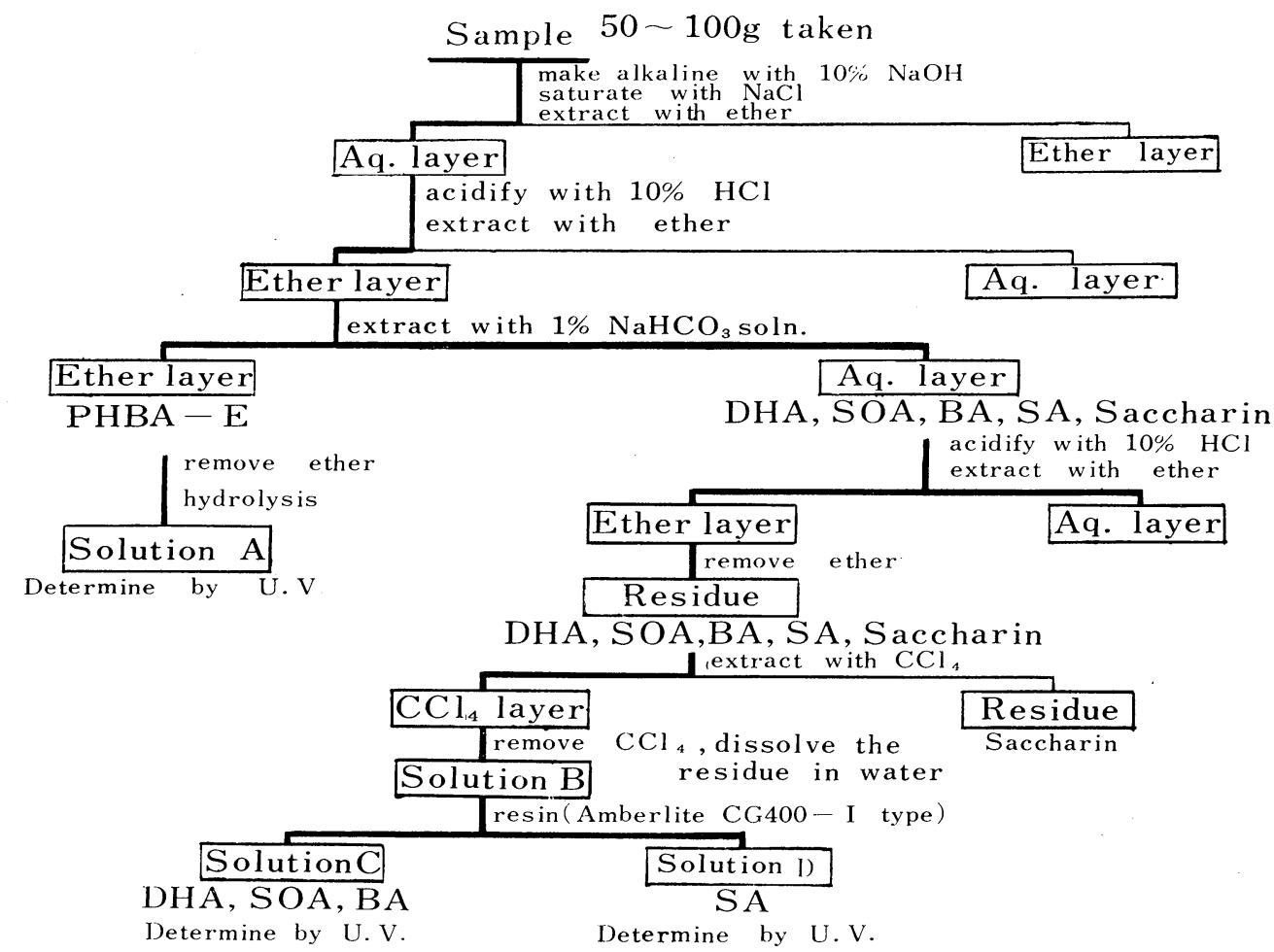

Fig. 2. Procedure of analytical method of the preservatives in focd; 
2. 溶離液 : $0.1 \mathrm{~N}$ 塩酸， $0.1 \mathrm{~N}$ 塩酸 $60 \%$ エタノール溶 液

\section{[試験操作]}

\section{1. 試料溶液の調製}

液体試料：保存料の含量に応じ試料 $50 \sim 100 \mathrm{~g}$ をとり, 必要あれば水を加えて全量を $100 \sim 150 \mathrm{ml}$ とし試料溶液 とする.

固体試料：試料を細切またはすりつぶし，保存料の含 量に応じその30～50 g を200 mlの三角フラスコにとり， 水 $100 \mathrm{ml}$ を加え， $10 \%$ 水酸化ナトリウム溶液でアルカ リ性とし，水浴上で加温してしばらく放置したのちろ過 する. 残留物は少量の水で洗い洗液をろ液に合し試料溶 液とする.

\section{2. 試験溶液の調製}

試料溶液を分液ロートにとり $10 \%$ 塩酸または $10 \%$ 水酸 化ナトリウム溶液で中和したのち，あらためて $10 \%$ 水酸 化ナトリウム溶液 $3 \mathrm{ml}$ を加えてアルカリ性とし，塩化 ナトリウムを飽和させ，エーテル $50 \mathrm{ml}$ で 3 回振りェー テル層を除く。つぎに水層を $10 \%$ 塩酸で十分に酸性にし たのちエーテル $50 \mathrm{ml}$ で 3 回抽出する.エーテル間を合 し水 $10 \mathrm{ml}$ で 2 回水洗したのち $1 \%$ 炭酸水素ナトリウム 溶液 $30 \mathrm{ml}$ で 3 回抽出する. エーテル層は無水硫酸ナト リウムで脱水しェーテルを留去する．残留物に $10 \%$ 水酸 化ナトリウム溶液 $2 \mathrm{ml}$ および水 $3 \mathrm{ml}$ を加え還流冷却器 を付し，石綿付金網上で15分間煮沸したのち，冷却し， $10 \%$ 塩酸 $5 \mathrm{ml}$ を加え酸性としエーテル $40 \mathrm{ml}$ で 3 回抽 出する.エーテル層を合し水 $10 \mathrm{ml}$ で 2 山水洗しエーテ ルを留去する. 残留物に $0.1 \mathrm{~N}$ 水酸化ナトリウム溶液 2 〜 $3 \mathrm{ml}$ を加えて溶かし，0.1 N 塩酸で中和したのち水を 加えて $100 \mathrm{ml}$ とし，これを試験溶液 Aとする。

つぎに，1\%炭酸水素ナトリウム溶液で抽出した水層 を合わせ，10\%塩酸で酸性としたのち塩化ナトリウムを 飽和させ，エーテル $50 \mathrm{ml}$ で 3 回抽出し，エーテル層を 水 $10 \mathrm{ml}$ で 2 回洗い, 無水硫酸ナトリウムで脱水しエー テルを留去する，この残留物に四塩化炭素 $5 \mathrm{ml}$ を加え て溶かし，乃過し，不溶物を少量の四塩化炭素で洗い， 洗液はろ液に合し，全量を正確に $10 \mathrm{ml}$ とする，その 5 $\mathrm{ml}$ をとり軽く送風しながら四塩化炭素を除去する. 残 留物に0. $1 \mathrm{~N}$ 水酸化ナトリウム溶液 $1 \sim 2 \mathrm{ml}$ を加えて溶 かし， $0.1 \mathrm{~N}$ 塩酸で中和したのち，水を加えて $100 \mathrm{ml}$ と しこれを試験溶液 B とする。

試験溶液 B 中に SA が共存するときはさらにつぎの 操作を行なら。

Fig. 1 に示すクロマト管に精製した Amberlite CG 400-I 型 (-Cl 形) を詰め, これに試験溶液 B $50 \mathrm{ml}$ を $1 \mathrm{ml} / \mathrm{min}$ で流下させ，続いて水 $50 \mathrm{ml}$ で水洗する．洗 液の滴下が終ったならば直ちに $0.1 \mathrm{~N}$ 塩酸 $250 \mathrm{ml}$ を用い て同じ流速で溶出を行ないこれを試験溶液 C とする．つ いで， $0.1 \mathrm{~N}$ 塩酸 $60 \%$ エタノール溶液 $50 \mathrm{ml}$ を用い同様
に溶出を行ないこれを試験溶液Dとする.

3. 定性

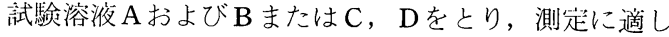
た濃度に希䣋し，その $10 \mathrm{ml}$ をとり緩衝液 $1 \mathrm{ml}$ を加え 自記分光光度計を用い，水 $10 \mathrm{ml}$ に緩衝液 $1 \mathrm{ml}$ を加え たものを対照とし紫外部吸収を測定する。ただし，C， Dについてはそれぞれの溶離液を対照とする.

PHBA-E が存在するときには試験溶液 $\mathrm{A}$ で波長 256 $\mathrm{m} \mu$ 付近に極大吸収を認める。 また, DHA, SOA, BA, $\mathrm{SA}$ がそれぞれ単独で存在するときは試験溶液 Bで, DHA は波長 $308 \mathrm{~m} \mu, 225 \mathrm{~m} \mu$, SOA は波長 $265 \mathrm{~m} \mu$, $\mathrm{BA}$ は波長 $230 \mathrm{~m} \mu, \mathrm{SA}$ は波長 $303 \mathrm{~m} \mu, 236 \mathrm{~m} \mu$ 付近に それぞれ極人吸収を諗める。これらが二者以上共存する ときにはそれぞれの含量に応じた合成波を認める。試験 溶液 C では DHA，SOA，BA の吸収が，芸験溶液 D では SA のみの吸収が認められる。

4. 定 雎:

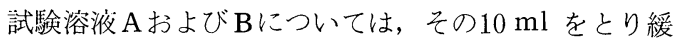
衝液 $2 \mathrm{ml}$ および水を加えて全量を $20 \mathrm{ml}$ とし, 必要に 忘じて10倍に薄めた緩衝液を用いて測定に適した濃度に 薄めたものにつき，各保存料の吸収極大波長付近におけ る吸光度を測定する。一方，各保存料の標準溶液から得 られた吸光度から保存料の含量を算出する. 試験溶液 C およびDについては測定に適した濃度に各溶離液を用い て薄め吸光度を測定する。一方，各保存料の標準溶液に ついてイオン交換樹脂を用いて同様に操作して得た吸光 度から保存料の含量を算出する.

\section{III 実験結果および考察}

本実験においては四塩化炭素によるサッカリンの分離 とイオン交換樹脂によるサリチル酸と他の保存料との分 離に主眼をおいて行なったものである.

1. サッカリンの分離について

四塩化炭素によるサッカリンの分離についてはすでに 著者らが前報2〕で述べたように保存料が四塩化炭素に 溶解するのに対しサッカリンはきわめて難溶である.

Table 1 は保存料およびサッカリン $0.5 \mathrm{~g}$ について四塩

Table 1. Solubility of Several Preservatives and Saccharin in $\mathrm{CCl}_{4}$

\begin{tabular}{|c|c|c|}
\hline Sample & $\begin{array}{l}\text { Soluble } \mathrm{mg} \text { in } \\
\mathrm{CCl}_{4} 10 \mathrm{ml}\end{array}$ & Solubility \\
\hline Dehydroacetic acid(DHA) & $349 \mathrm{mg}$ & $3.5 \%$ \\
\hline Sorbic acid (SOA) & $107 \mathrm{mg}$ & $1.1 \%$ \\
\hline Benzoic acid (BA) & $488 \mathrm{mg}$ & $4.9 \%$ \\
\hline Salicylic acid (SA) & $34 \mathrm{mg}$ & $0.3 \%$ \\
\hline $\begin{array}{r}\text { Ethyl-p-hydroxybenzoate } \\
\text { (PHBA-Et.) }\end{array}$ & $13 \mathrm{mg}$ & $0.1 \%$ \\
\hline $\begin{array}{r}\text { Propyl-p-hydroxybenzoate } \\
\text { (PHBA-Pr.) }\end{array}$ & $31 \mathrm{mg}$ & $0.3 \%$ \\
\hline $\begin{array}{r}\text { Butyl-p-hydroxybenzoate } \\
\text { (PHBA-Bu.) }\end{array}$ & $>500 \mathrm{mg}$ & $>5.0 \%$ \\
\hline Saccharin & $<1 \mathrm{mg}$ & 0 \\
\hline
\end{tabular}


化炭素10 ml に対する溶解度をみたものである.

また，サッカリンおよび保存料を四塩化炭素に溶かし ろ過したろ液についての赤外吸収スペクトルを測定して みたところ保存料の吸収は現われるが，サッカリンの吸 収は見られずサッカリンの四塭化炭素に対する不溶性を 示している.

2. 二種のイオン交換樹脂の比較

イオン交換クロマトグラフ用 Amberlite CG 4B-I 型
(100 200 メッシュ) および Amberlite CG 400-I·型 （100〜200メッシュ）について検討した.

\section{(i) Amberlite CG 4 B-I 型}

本樹脂については Table 2 および Fig. 3 に示すよう にイオン交換の不完全なものがあり，また溶出曲線のピ ークが重なるものが多く，100\% 溶出の困難なものがあ る. したがってこの樹脂は保存料の分離には不適当と思 われる.

Table 2. Exchange and Elute Rates of Preservatives

\begin{tabular}{|c|c|c|c|c|c|c|c|}
\hline \multirow{2}{*}{\multicolumn{2}{|c|}{ Preservatives (mg) }} & \multicolumn{3}{|c|}{ Amberlite CG 4B-I } & \multicolumn{3}{|c|}{ Amberlite CG 400-I } \\
\hline & & $\begin{array}{c}\text { Exchange rate } \\
(\%)\end{array}$ & Elute & rate $(\%)$ & $\begin{array}{c}\text { Exchange rate } \\
(\%)\end{array}$ & Elute & rate $(\%)$ \\
\hline DHA & 3 & 100 & & $\begin{array}{ll}* 1 & 60\end{array}$ & 100 & & *1 100 \\
\hline SOA & 10 & 100 & & *1 100 & 100 & & *1 100 \\
\hline $\mathrm{BA}$ & 10 & 100 & & *1 100 & 100 & & *1 100 \\
\hline SA & 1 & 100 & & $* 1 \quad 70$ & 100 & & $\begin{array}{rr}* 1 & 90 \\
* 2 & 100\end{array}$ \\
\hline PHBA-Et. & 1 & 20 & & $\begin{array}{ll}* 1 & 20\end{array}$ & 100 & & *3 100 \\
\hline PHBA-Pr. & 1 & 70 & & $* 1 \quad 66$ & 100 & & *3 100 \\
\hline PHBA-Bu. & 1 & 80 & & $* 1 \quad 65$ & 100 & & *3 100 \\
\hline
\end{tabular}

*1 by $0.1 \mathrm{~N} \mathrm{HCl}$

*2 by $0.1 \mathrm{~N} \mathrm{HCl}$ with $60 \%$ Ethanol

$* 3$ by $60 \%$ Ethanol soln.
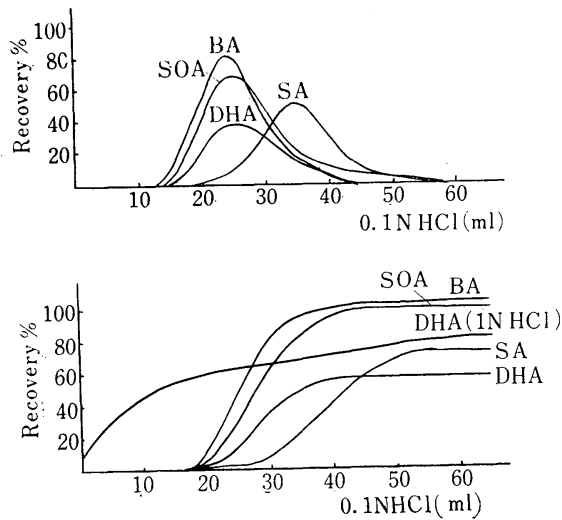

Fig. 3. Recovery of several preservatives eluted with $0.1 \mathrm{~N} \mathrm{HCl}$ by ion-exchange resin (Amberlite CG 4B-I)

(ii) Amberlite CG 400-I 型

いずれの保存料も100\%交換され，Table 2, Fig. 4 に 示すように0.1N塩酸によってほぼ100\%溶出される。す なわち，DHA は $0 \sim 60 \mathrm{ml}$, SOA は30〜 $100 \mathrm{ml}, \mathrm{BA}$ は60〜250 ml あたりにかけてほぼ100\%溶出する. SA は220 ml あたりから徐々に溶出がはじまり約 $300 \mathrm{ml}$ 中

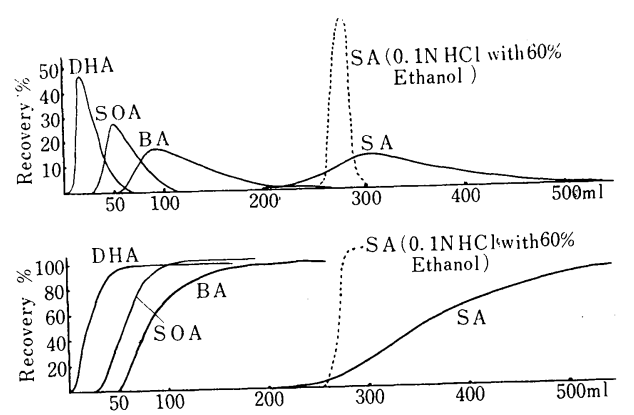

Fig. 4. Recovery of several preservatives eluted with $0.1 \mathrm{~N} \mathrm{HCl}$ by ion-exchange resin (Amberlite CG 400-I)

にほぼ90\%溶出するが PHBA-E は溶出してこない.

以上の検討から保存料の分離には CG 400-I 型が適当 と思われるので以下の実験は CG 400-I 型を用いて行な ろことにした。

3. 溶離液についての検討

(i) 塩酸濃度

$0.02 \mathrm{~N}, \quad 0.1 \mathrm{~N}, 0.2 \mathrm{~N}, 0.5 \mathrm{~N}, 1 \mathrm{~N}$ 各濃度について 検討したが塩酸の濃度差による溶出の著しい変化は認め 
られない。

(ii) エタノール溶液の併用

$\mathrm{SA}$ の溶出は0.1N塩酸では300 ml を要し時間的に奏 用性を欠くので, この溶出をすみやかに行なう点につい て検討した。 Fig. 5 に示すように SA は $0.1 \mathrm{~N}$ 塩酸 300 $\mathrm{ml}$ を用いる代りに0.1 N塩酸 $60 \%$ エタノール溶液 $50 \mathrm{ml}$ を用いると容易に溶出が行なえることがわかる.

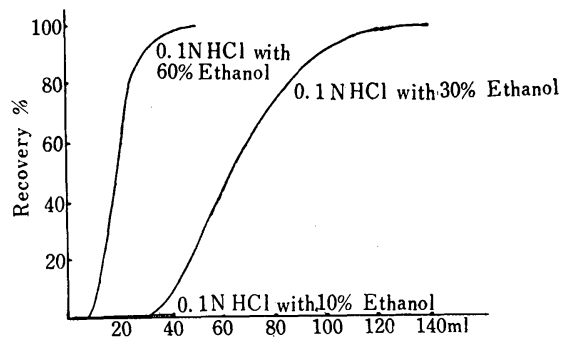

Fig. 5. Eluting result of $\mathrm{SA}$ by $0.1 \mathrm{~N} \mathrm{HCl}$ with $60 \%$ ethanol

(iii) 樹脂層の長さ

樹脂の充填の長さと保存料相互の分離状態をみるため 2 倍の長さの $10 \mathrm{~cm}$ 拉よ゙ 3 倍の長さの $15 \mathrm{~cm}$ について 検討したのが Fig. 6 である. 層の長さが長くなるほど 保存料相互の分離はよくなり, DHA と BA とは完全に 分離でき, $\mathrm{SOA}$ とA もほとんど分離できる. しかし 同時に溶離液も多量を要し, 溶出時間も長くなり実用性 にかける。 BA，SOA，DHA は共存しても紫外部吸収 測定でかなりの精度で分別定量が可能であるから $5 \mathrm{~cm}$ の長さでも十分であると考える (Fig.4).

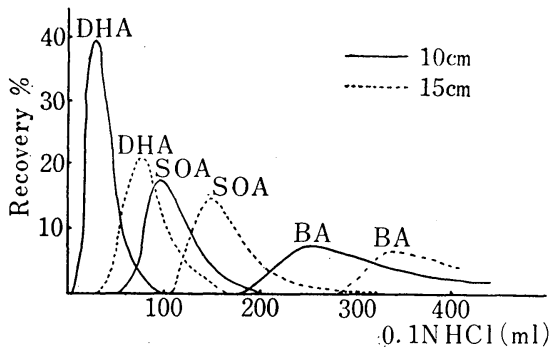

Fig. 6. Effect of column length

(iv) 滴下速度

樹脂の長さ $5 \mathrm{~cm}$ の条件において溶出液の滴下速度を $1 / 2(0.5 \mathrm{ml} / \mathrm{min})$ にしたときの DHA, SOA, BA の分 離状態をみた。その結果は Fig. 7 に示すように滴下速 度 $1 \mathrm{ml} / \mathrm{min}$ (Fig. 4) と比べてとくに分離がよくなら ない.

\section{PHBA-E の溶出試験}

PHBA-E は本法の場合, 抽出操作の途中で分別して いるのでとくに問題はないが，Amberlite CG 400-I 型

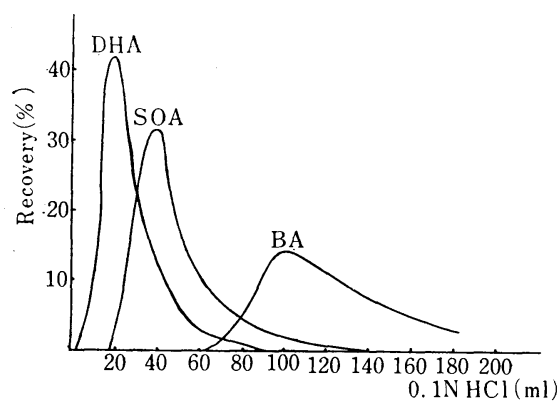

Fig. 7. Effect of flow rate, $0.5 \mathrm{ml} / \mathrm{min}$

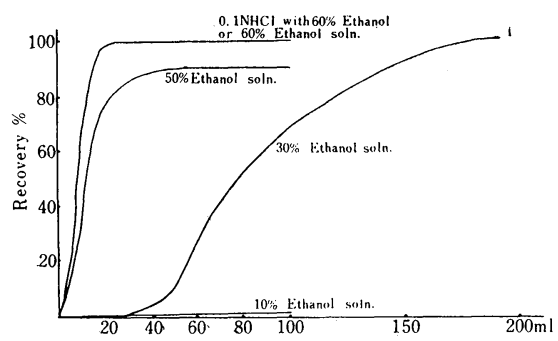

Fig. 8. Eluting result of PHBA-Bu. by ethanol solutions

についての溶出状態をみると, 使用した PHBA-E の-ェ チル，ープロピル，ーブチルではともに $0.1 \mathrm{~N}$ 塩酸 $200 \mathrm{ml}$, $0.5 \mathrm{~N}$ 塩酸 $100 \mathrm{ml}, 1 \mathrm{~N}$ 塩酸 $100 \mathrm{ml}$ 中には溶出しないが, ーブチルの場合 $10 \%, 30 \%, 50 \% ， 60 \%$ エタノール溶液で は Fig. 8 のように溶出する.

また， $0.1 \mathrm{~N}$ 塩酸 $60 \%$ エタノール溶液でも $20 \mathrm{ml}$ まで に溶出するので SA と PHBA-E とが共存しているとき は，はじめに SA を全く溶出しない $60 \%$ エタノール溶 液で PHBA-E のみを溶出させたのち $0.1 \mathrm{~N}$ 塩酸 $60 \%$ エ タノール溶液で $\mathrm{SA}$ を溶出させればよい.

5. 混合保存料についての分離試験

3.の（i)〜（iv）の検討に基づいて保存料の標準品を混 合した試料を分析した結果を Table 3 に示す. 分離法 は内径 $1 \mathrm{~cm}$ のカラム（Fig. 1) を用い，常法に従って 精製し -Cl 形とした Amberlite CG 400-I 型を $5 \mathrm{~cm}$ の 長さに詰め，DHA，SOA，BA およびSAの $1 〜 10 \mathrm{mg}$ を混合したものをイオン交換させたのち各溶離液を用い て $1 \mathrm{ml} / \mathrm{min}$ の速度で溶出を行なう。すなわち $0.1 \mathrm{~N}$ 塩酸を用いて $60 \mathrm{ml}$ までのフラクション（I）と 60〜 $250 \mathrm{ml}$ までのフラクション（II）に分取し，ついで0.1 $\mathrm{N}$ 塩酸 $60 \%$ エタノール溶液を用いて50 ml のフラクショ ン（III）をとる．各フラクションにつき必要に応じてそ れぞれの溶離液で希釈し，各保存料の吸収極大波長で吸 光度を測定する.すなわち， 
（I）においては

波長 $308 \mathrm{~m} \mu(\mathrm{DHA})$, 波長 $265 \mathrm{~m} \mu$ (SOA)

(II)においては 波長 $265 \mathrm{~m} \mu$ (SOA), 波長 $230 \mathrm{~m} \mu$ (BA)

（III）においては 波長 $303 \mathrm{~m} \mu$ (SA)
での吸光度を求め, あらかじめ作成した検量線から含量 を求め, (II) は BA と SOA とが共存しているので 前報1)で述べたような理由から $\mathrm{BA}$ の吸光度を補正して 求めた。

Table 3. Recovery of Mixed Several Preservatives by Ion Exchanger Method

\begin{tabular}{|c|c|c|c|c|}
\hline $\begin{array}{l}\text { Mixed preservatives } \\
\text { Elutes }\end{array}$ & DHA $\quad 5 \mathrm{mg}$ & SOA $10 \mathrm{mg}$ & $10 \mathrm{mg}$ & $1 \mathrm{mg}$ \\
\hline $\begin{array}{l}0.1 \mathrm{~N} \mathrm{HCl} \\
0 \sim 60 \mathrm{ml}\end{array}$ & $\begin{array}{l}4.9 \mathrm{mg} \\
4.9 " 1 \\
5.0 " \\
4.9 "\end{array}$ & $\begin{array}{l}9.0 \mathrm{mg} \\
9.0 " 1 \\
9.0 " 1 \\
9.0 "\end{array}$ & & \\
\hline $\begin{array}{l}0.1 \mathrm{~N} \mathrm{HCl} \\
61 \sim 250 \mathrm{ml}\end{array}$ & & $\begin{array}{l}1.7 \mathrm{mg} \\
1.5 " 1 \\
1.5 " \\
1.5 "\end{array}$ & $\begin{array}{l}9.5 \mathrm{mg} \\
9.5 " 1 \\
9.7 " \\
9.8 "\end{array}$ & \\
\hline$\left(\begin{array}{l}0.1 \mathrm{~N} \mathrm{HCl} \\
251 \sim 550 \mathrm{ml}\end{array}\right)$ & & & & $\left(\begin{array}{ll}0.90 & \mathrm{mg} \\
0.88 & \prime \prime \\
0.84 & \prime \prime \\
0.85 & \prime \prime\end{array}\right)$ \\
\hline $\begin{array}{l}0.1 \mathrm{~N} \mathrm{HCl} \text { with } 60 \% \\
\text { Ethanol } 50 \mathrm{ml}\end{array}$ & & & & $\begin{array}{l}0.91 \mathrm{mg} \\
0.88 " \\
1.00 " \\
0.97 "\end{array}$ \\
\hline Total & $\begin{array}{l}4.9 \mathrm{mg} \\
4.9 " 1 \\
5.0 " 1 \\
4.9 "\end{array}$ & $\begin{array}{l}10.7 \mathrm{mg} \\
10.5 " \\
10.5 " \\
10.5 "\end{array}$ & $\begin{array}{l}9.5 \mathrm{mg} \\
9.5 " 1 \\
9.7 " \\
9.8 "\end{array}$ & $\begin{array}{l}0.91 \mathrm{mg} \\
0.88 " \\
1.00 " \\
0.97 "\end{array}$ \\
\hline Means & $4.9 \mathrm{mg}$ & $10.6 \mathrm{mg}$ & $9.6 \mathrm{mg}$ & $0.94 \mathrm{mg}$ \\
\hline Recovery $(\%)$ & $98 \%$ & $106 \%$ & $96 \%$ & $94 \%(87 \%)$ \\
\hline
\end{tabular}

各フラクションの盲吸収をみると波長が短いほど影響 を受けやすいが目的物質の濃度が高く 10 倍あるいは 100 倍希釈で吸光度を測定するので害際には盲吸収の影響は ほとんどない.

6. Amberlite CG 400-I 型による妨害物質の除去 ある種の乳酸菌飲料, 煮豆, ジャム，みそなどに含有 する保存料を水蒸気蒸留法を用いて分離するとき, 留液 中に同時に香料その他食品由来の物質が留出し保存料の 紫外部吸収が妨害され保存料の有無を判定しかねること がある.この場合, 水蒸気蒸留法では抽出操作でこの妨 書を除いているが，この抽出操作の代りに Amberlite CG 400-I 型を用いることもできる. Fig. 9 は DHA お よび SOA を含有するみその留液について紫外部吸収ス ペクトル，およびこれの Amberlite CG 400-I 型処理 による紫外部吸収スペクトルを示す。

Fig. 10 は DHA $0.016 \mathrm{~g} / \mathrm{kg}$ を含有するぎょうざの皮 について水蒸気蒸留を行ない, ここに得た留液とこの留 液 $210 \mathrm{ml}$ を Amberlite CG 400-I 型処理により $70 \mathrm{ml}$
に濃縮したものについて試験溶液を調製し，両者の紫外 部吸収スペクトルを比較したものである。したがってイ オン交換操作は留液の濃縮操作として用いることもでき る.
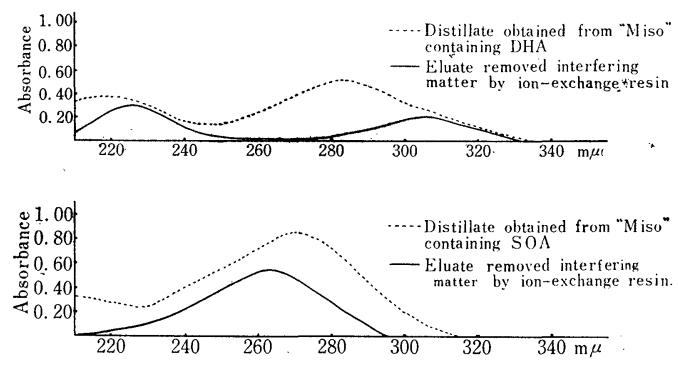

Fig. 9. U.V. spectra of distillate obtained from "Miso" containing DHA or SOA and eluate treated by ion-exchange resin (Amberlite CG 400-I) 


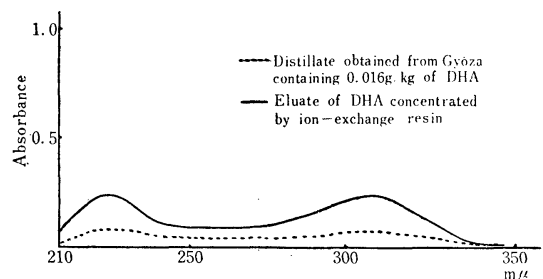

Fig. 10. U.V. spectra of distillate obtained from "Gyōza" containing 0.016 g/ $\mathrm{kg}$ of DHA and eluate treated dy ion-exchange resin (Amberlite CG 400-I)

\section{IV 市販品についての検查成績}

本法でジュース，漬物類中の保存料を分析した結果は Table 4 である.この種の食品には SA を含有するこ とが少ないので今回はイオン交換樹脂による SA と他の 保存料との分離操作はとくに行なおなかった。

$\mathrm{V}$ むす び

DHA，SOA，BA，SA および PHBA-E の酸性保存
料掞よびサッカリンを含む食品について保存料の溶媒抽 出およびイオン交換樹脂を用いる分離定性定量法を検討 した.とくにサッカリンの保存料からの分離㧍よび SA と他の保存料との分離に主眼をおき以下の結果を得た。

(1) 保存料とサッカリンとは四塩化炭素に対する溶解 度の差でほぼ完全に分離できる.

(2) Amberlite CG 400-I 型を用いれば SA を DHA, $\mathrm{BA}, \mathrm{SOA}$ と分離できる. また, 樹脂層の長さを長くす れば $\mathrm{DHA} と \mathrm{BA}$ との分離抢よび $\mathrm{SOA}$ と $\mathrm{BA}$ との分 離も可能である.

(3) Amberlite CG 400-I 型を用いれば水蒸気蒸留法 の際, 留液中にみられる紫外部吸収スペクトルの妨害除 去操作に代えられる. また, 水蒸気蒸留法による試験溶 液中の保存料濃度の濃縮操作としても有効である.

本報告は第10回日本食品衛生学会(昭和 40 年10月 27 日， 東京)において発表.

文献

1）菅野三郎, 井上哲男, 他：食衛誌. 7, 72(1966)。

2）井上哲男，河村太郎，他：食衛誌. 5, 368(1964).

Table 4. Experimental Results of Market Juices and Pickles

\begin{tabular}{|c|c|c|c|c|c|}
\hline Sample & DHA $\mathrm{g} / \mathrm{kg}$ & SOA $\mathrm{g} / \mathrm{kg}$ & $\mathrm{BA} \mathrm{g} / \mathrm{kg}$ & $\mathrm{SA} \mathrm{g} / \mathrm{kg}$ & PHBA g/kg \\
\hline Orange juice (1) & 0.026 & negative & negative & negative & negative \\
\hline " $\quad(2)$ & negative & " & 0.015 & $"$ & " \\
\hline Pine juice & 0.01 & " & 0.017 & " & " \\
\hline Melon juice & 0.07 & $"$ & 0.025 & " & $"$ \\
\hline Orange conc. juice & 0.055 & " & 0.28 & " & 0.015 \\
\hline Lemon conc. juice & 0.015 & " & 0.09 & $"$ & 0.006 \\
\hline Strawberry syrup & 0.063 & " & 0.25 & " & 0.014 \\
\hline Melon syrup & 0.34 & $" 1$ & 0.218 & " $"$ & negative \\
\hline Cucumber soaked in "Soy sauce" & negative & 0.56 & negative & " & " \\
\hline Vegetables soaked in "Soy sauce" & " & 0.30 & " & $"$ & " \\
\hline "Hana-rakkyo" & " & 0.12 & " & $" 1$ & " \\
\hline Ginger root soaked in "Miso" & " & 0.38 & " & " & " \\
\hline
\end{tabular}

